\title{
Impact of income on nutrient intakes: implications for undernourishment and obesity
}

Article

Accepted Version

Salois, M. J., Tiffin, R. and Balcombe, K. G. (2012) Impact of income on nutrient intakes: implications for undernourishment and obesity. Journal of Development Studies, 48 (12). pp. 1716-1730. ISSN 1743-9140 doi:

https://doi.org/10.1080/00220388.2012.658376 Available at https://centaur.reading.ac.uk/25024/

It is advisable to refer to the publisher's version if you intend to cite from the work. See Guidance on citing.

To link to this article DOI: http://dx.doi.org/10.1080/00220388.2012.658376

Publisher: Taylor and Francis

All outputs in CentAUR are protected by Intellectual Property Rights law, including copyright law. Copyright and IPR is retained by the creators or other copyright holders. Terms and conditions for use of this material are defined in the End User Agreement.

www.reading.ac.uk/centaur 
Central Archive at the University of Reading

Reading's research outputs online 
Impact of Income on Nutrient Intakes: Implications for Undernourishment and Obesity

\begin{abstract}
The relationship between income and nutrient intake is explored. Nonparametric, panel, and quantile regressions are used. Engle curves for calories, fat, and protein are approximately linear in logs with carbohydrate intakes exhibiting diminishing elasticities as incomes increase. Elasticities range from 0.10 to 0.25 , with fat having the highest elasticities. Countries in higher quantiles have lower elasticities than those in lower quantiles. Results predict significant cumulative increases in calorie consumption which are increasingly composed of fats. Though policies aimed at poverty alleviation and economic growth may assuage hunger and malnutrition, they may also exacerbate problems associated with obesity.
\end{abstract}

Keywords: calorie and nutrient consumption, food and nutrition policy, income elasticities, nonparametric, panel, quantile regression. 


\section{Introduction}

The number of undernourished people in the world increased from 854 million in 2006 to an estimated 1.02 billion in 2009 , representing the greatest amount of hungry people in nearly half a century (FAO 2009). The FAO (2009) contends that while the current economic crisis plays a role in the global escalation of hunger, surging domestic food prices and deteriorating household incomes are especially to blame. Paradoxically, the growing international prevalence of hunger and starvation resulting from energy and nutrient deficiencies continues amidst global concern regarding the rapidly increasing prevalence of chronic diseases resulting from overweight and obesity. As of 2005, an estimated 1.6 billion adults over age fifteen were overweight and 400 million were obese (WHO 2006). Although the spread of obesity was confined historically to the developed countries, emerging trends indicate the growth of overweight and obesity in the developing world (Hossain et al. 2007). In fact, in many developing countries both childhood malnutrition and adult obesity are concurrently observed within households resulting in a "dual burden of disease" (Doak et al. 2004; Caballero 2005). The links between economic growth, nutrition, and health highlight the importance of understanding the relationship between income and nutritional status. Poor nutrition can spur a cycle leading to poor health which in turn results in low productivity and diminished economic growth with further declines in nutrition. Nutritional status plays an important role in a number of health and socio-economic indicators including the prevalence of disease, educational attainment, and labour market outcomes (Pinstrup-Andersen 2007).

A potential key determinant of nutritional status is income. Therefore, studies on the relationship between income and nutrient intake receive considerable attention. Knowledge of these elasticities is a critical component in the design of policies to combat malnutrition in poor countries and to improve diets in both rich and poor countries. For example, a large elasticity suggests a policy designed to increase the income of the poor and promote 
economic growth is an effective long-term strategy. Conversely, a small elasticity suggests limited scope for income-enhancing economic policies. Just as important, knowing how calorie and nutrient elasticities change with income becomes necessary in light of the obesity epidemic. The process of economic development spurs a "nutrition transition" in which diets high in carbohydrates are replaced with more varied diets high in fat (Popkin 1994). If calorie-income elasticities show no indication of decreasing at higher incomes there is a stronger need for public programs to influence diets in developed and developing countries.

Estimates of the income elasticity are abundant and the true approximate magnitude remains a controversial topic because of the wide range of estimates. Bouis and Haddad (1992) provide a good review and find elasticity estimates in the range of 0.01 to 1.18 . With the evidenced mixed, the debate persists regarding the actual relationship between nutrient intake and income and the appropriate economic policies for combating hunger and malnutrition. Also left unclear is the extent the nutrition transition is expected to occur in the developing economies, which involves not only a worsening in diet quality across the developing world but also a likely global epidemic from diet-related chronic disease. The role of income in nutrition is clearly important for developing countries. However, as people in developed countries consume calories at increased levels, asking if further increases in income are likely to aggravate problems associated with obesity also becomes important.

The objective of this paper is to assess the relationship between income and nutrient intake in a cross-national sample of developing and developed countries across two different time periods. This paper aims to determine if there is a significantly positive relationship between income and calorie-macronutrient intakes. This paper contributes to the literature in three ways. First, while most studies tend to focus on one country in a single year using household-level data, the data also allow the nutrient-income relationship to vary between levels of economic development and between time periods, which provides a broader view of 
assessing the nutrition transition. Estimates from an aggregate Engel curve using international data also provide a global perspective and generalize results at a macroeconomic level.

Second, while the literature tends to focus on calorie intakes, this paper decomposes calories into three important macronutrients (carbohydrates, proteins, and fats), permitting the relationship with income to differ between nutrients. Income elasticity estimates that break down calorie intake into individual nutrients are important from a policy perspective. For example, economic growth may increase total calorie intake, reducing problems related to undernutrition, but may also result in a greater proportion of fat in the diet, aggravating problems of obesity and diet-related chronic diseases. The income-calorie elasticity alone is not enough to guide policy makers. Understanding the general composition of the diet and the consumption of particular nutrients becomes crucial in this context.

Third, three estimators are utilized: panel regression, nonparametric regression, and quantile regression. Most studies assume a parametric relationship, which imposes strict assumptions. In addition to using a panel estimator to test for time-effects, this paper also uses a nonparametric estimator. Since the nonparametric approach lets the relationship be both non-linear and non-monotonic, calorie intakes between poor households and rich households can respond differently to income. Quantile regression assesses the heterogeneity in intake response to income across countries over time. Since the effect of income may differ across the distribution of calorie intake, particular segments of the intake distribution are of great interest, especially from a public health and nutrition policy perspective.

\section{Literature Review}

Historically, the "conventional wisdom" of the World Bank and other development institutions was that deficient energy intake and hunger can be assuaged through income growth (World Bank 1980, 1981). However, a series of articles emerged in the 1980s casting doubt on the role of income (Wolfe and Behrman 1983; Behrman and Wolfe 1984; Behrman 
and Deolalikar 1987). The role of income continues to be interest since contrasting results appear throughout the literature. While the positive relationship between nutrient intake and income is reinforced in some studies, other studies find either small or insignificant income elasticities (Sahn 1988; Ravallion 1990; Bouis 1994). Although a substantial literature warns against an income-focused policy, the role of income is still considered important by many institutions. According to the latest FAO (2009, p.36) report on food insecurity, the recent "diminished economic access to food because of higher prices was compounded by lower incomes." While a number of early papers substantiate the conventional wisdom of the World Bank before the "revisionist" papers emerged in the 1980s (Pinstrup-Andersen and Caicedo 1978; Ward and Sanders 1980), more recent studies further counter the revisionist regime (Subramanian and Deaton 1996; Dawson and Tiffin 1998; Tiffin and Dawson 2002; Abdulai and Aubert 2004) and emphasize an income-drive approach. Table 1 provides a summary of recent studies since the review in Bouis and Haddad (1992). The estimated calorie elasticities are of moderate magnitude (between 0.2 and 0.5 ) and most authors conclude that improving income is crucial to combating malnutrition.

The existing evidence on income elasticities for nutrient intake from single-country studies reveals considerable differences (Pitt and Rosenzweig 1985; Berhman and Deolalikar 1989). Different approaches partly explain the variation in estimates. One important difference is how the Engel curve and resulting income elasticity is estimated. Generally two approaches to estimate the income-calorie relationship are followed in the literature. The first approach uses individual level data obtained from household surveys. Some micro-level studies follow an indirect approach and use food expenditure survey data to estimate a model of food demand and then convert food demand elasticities into nutrient demand elasticities. Other micro-level studies opt for a direct approach and use food diaries based on individual dietary intake recall to estimate the nutrient-income elasticities directly. The second approach 
uses aggregate data on average per capita dietary energy supply derived from national food balance sheets. Aggregate studies either employ annual time series data for a specific country or use cross-sectional data on a number of countries in a specific year. Studies using aggregate data tend to obtain smaller elasticities than those that use more micro-level data.

Even if reasonably sized and statistically significant income-calorie elasticities are found, the role of income in nutritional status is still unclear since people may shift the composition of their nutrient consumption as income increases (Behrman and Deolalikar 1989). Evidence suggests that as incomes rise household expenditure on food increases because more expensive food is being purchased, but the nutrient content of these foods does not increase proportionately (Pitt 1983; Behrman, Deolalikar, and Wolfe 1988). Improvements in income may result in increases in food expenditures or total calorie intake but this may not coincide with a diet more rich in nutrients (Behrman and Deolalikar 1987). Households tend to increase the variety of their diet based on features other than nutrient content, such as taste and quality, as they substitute away from cheaper sources of calories towards more expensive ones. Conversely, studies that uncover a small or zero elasticity do not necessarily imply that a change in income does not affect nutrition. For example, a drop in income may result in unchanged calorie intake, but the consumption of vital nutrients may fall as households substitute towards cheaper and less nutritious foods.

In addition to problems of deficient calorie and nutrient intake is the problem of excessive intake leading to overweight and obesity. The World Health Organization (2006) projects that by 2015 nearly 2.3 billion adults will be overweight and over 700 million will be obese. As developing countries experience economic growth, overweight and obesity are on the rise in low- and middle-income countries, particularly in urban areas (WHO 2006). Higher income countries tend to obtain most of their dietary energy supply from fat (Drewnowski 2003). The analysis in Drewnowski and Popkin (1997) reveals a global 
convergence towards a diet deriving a higher proportion of energy from fat across a sample of developed and developing countries. Specifically, they warn about the possibility that a diet containing close to $30 \%$ of energy from fat could become the global norm. Also worrying is the trend that the nutrition transition is occurring at lower levels of income than previously thought. As pointed out in Popkin and $\mathrm{Ng}$ (2007, p.200), "even poor nations had access to a relatively high-fat diet by 1990 when a diet deriving $20 \%$ of energy (kilocalories) from fat was associated with countries that have a GNP of only $\$ 750$ per capita".

\section{Data and Econometric Methods}

A cross-sectional sample of 171 developing and developed countries across two time periods (1990-1992 and 2003-2005) is constructed using national income and nutrient data (see the available appendix for countries included). Aggregate data on national income data is sourced from the International Financial Statistics of the International Monetary Fund and is the Gross Domestic Product (GDP) for each country in billions of 2005 U.S. dollars. To convert these values to per capita terms, population data is obtained from the Penn World Tables. Hence, income refers to GDP per capita and not household income or total expenditure. Aggregate data on average per capita dietary energy supply are derived from national food balance sheets obtained from the FAO Statistics Division. Dietary energy consumption per person is defined as the amount of food, in kilocalories per day, for each individual in the total population. The measure is based on food available for human consumption computed as the residual from the total food supply available from production and trade less waste and other non-food uses, such as from industry or agriculture (see FAO 1996 for a full description of the data). Similar data are constructed for key macronutrients including carbohydrates, proteins, and fats. It should be noted that the FAO uses countrylevel data on per capita energy and macronutrient supply to proxy per-capita intakes. Thus, when the term 'intake' is used availability data is being used to proxy actual intake. 
Three main estimation methods are employed in this paper. All three are Bayesian. First, there is the nonparametric approach outlined in Chapter 10 of Koop (2003). The second is a linear (in parameters) panel regression that can be estimated using the framework outlined in Chib and Greenberg (1995). Finally, the recently developed method for estimating quantile regressions (the Bayesian Exponentially Tilted Empirical Likelihood, BETEL method) outlined in Lancaster and Sung (2010). When using the panel approach, alternative models are evaluated using the Bayesian Deviance Information Criteria (DIC) outlined in Spiegelhalter et al. (2002). A full description of each of the methods can be found in the references above, therefore, the coverage here is succinct.

\section{The Nonparametric Approach}

The motivation for a nonparametric approach is because the relationships between calorie or nutrient consumption and incomes may be highly non-linear and plausibly nonmonotonic. Finding a nonlinear relationship implies the impact of income on calorie intake is affected by the actual level of calorie intake. For example, a higher income elasticity of calorie intake ought to be expected for poor households since they may have insufficient income to pay for adequate nutrition. On the other hand, high calorie consumers may not be as greatly affected by a marginal increase in income as low calorie consumers and as such

will have a smaller elasticity. Nonparametric procedures allow for such possibilities and mitigate problems of statistical bias resulting from an incorrectly specified parametric form. Some studies argue that the relationship is linear (Bhargava 1991), while other studies uncover important nonlinearities in the income-calorie relationship (Gibson and Rozelle 2005; Skoufias 2003). Of the studies that use nonparametric methods to investigate the potential for nonlinearities find they are not present (Subramanian and Deaton 1996; Abdulai and Aubert 2004), while other studies conclude the income elasticity is better described by a curve rather than a line (Roy 2001; Gibson and Rozelle 2002; Skoufias 2003). 
The flexibility of the nonparametric approach also allows the examination of whether simple functional forms may be viable. Therefore, the nonparametric approach is employed first before investigating the relationships using parametric methods. The nonparametric approach assumes:

$$
y_{i}=f \quad x_{i}+e_{i}
$$

where $y_{i}$ is the average consumption in country $i$ of calories or one of the nutrient groups, and $x_{i}$ is per capita income in country $i$. Alternatively $y_{i}$ and $x_{i}$ may be logged values of these variables. The error term $e_{i}$ is assumed to be independently and identically normally distributed. As outlined in Koop (2003), the nonparametric relationship can be modelled by estimating $f x_{i}$ at each point value of $x_{i}$. The estimation of the nonparametric relationship requires a smoothing parameter $\eta$ to be estimated. This parameter is analogous to bandwidth selection using classical kernel estimation. Within the Bayesian approach to estimation, this parameter can be estimated by maximizing the marginal likelihood of the relationship or through cross-validation, with the former method used (Koop 2003). When using the nonparametric approach, the models are estimated for the two periods separately. Thus, there are two sets of nonparametric regressions for each of the time periods.

\section{The Panel Approach}

The main benefit of the panel approach is an ability to control for both individual and temporal unobserved heterogeneity via group fixed effects and time fixed effects. Group fixed effects control for permanent differences between individual countries (i.e., differences across countries that are constant over time) while time fixed effects control for impacts common to all countries but that vary through time (i.e., differences over time that are common to all groups). For the panel approach, the models investigated are of the form

$$
y_{i t}=\alpha_{t}+\beta_{1 t} x_{i t}+\beta_{2 t} x_{i t}^{2}+\beta_{3 t} x_{i t}^{3}+e_{i t},
$$


where $e_{i t} \sim N 0, \sigma^{2}, E e_{i t}, e_{j t}=0$ for all $i \neq j$ and $E e_{i t}, e_{j t^{*}}=\rho \sigma^{2}$ where $t \neq t^{*}$. Also, $y_{i t}$ denotes the dependent variable (calories or nutrients or logs of these variables) for country $i$ at time $t$ and $x_{i t}$ is per capita income (or logged values) for country $i$ at time $t$. Since there are only two time periods, the values of $t$ are one and two. A cubic relationship deals with functions that have variable second derivatives whereby the function may be convex and concave over alternative regions of the variable space.

The imposition of restrictions are investigated, such as $\beta_{i t}=\beta_{i t^{*}}$ (no time effects) and/or $\beta_{2 t}=0$ and/or $\beta_{3 t}=0$, in which case the function may become quadratic or linear (or linear in logs). The Bayesian approach further allows imposition and investigation of whether inequality restrictions are consistent with the data. For example, in the cubic relationship the hypothesis might be that $\beta_{3 t}<0$ since consumption of calories or nutrients may not increase at an accelerating rate as incomes rise. An alternative panel approach (i.e., a "within country and between time" regression) assumes that $\beta_{j t}=\beta_{j t^{*}}$ for all $j$ along with $e_{i t^{*}}=e_{i t}+z_{i}$ is also estimated, where $z_{i}$ is a normally distributed country effect. Finally, a first-difference model regression is estimated.

\section{The Quantile Approach}

Concerns regarding obesity and hunger solicit special attention to the tails of the intake distribution, where dietary excess and deficiency occurs, rather than at the means. Since most previous studies rely on a form of ordinary least squares (either parametric or nonparametric), the marginal effects of income derived from these studies are assumed to be the same over the distribution of calorie intake. Since this is a very strong assumption, results from these studies are of limited value. Quantile regression relaxes this assumption and allows for heterogeneous responses of calorie intake to income. Despite the strong appeal of quantile regression in application to nutrition problems, very few studies employ them. The 
few that use a quantile approach focus on nutrient intakes for one country only (Fousekis and Lazaridis 2005; Skoufias et al. 2009; Shankar 2010).

Unlike the previous two approaches, the BETEL does not have an explicit functional form for the likelihood. Instead, the empirical likelihood is constructed by optimizing an entropy measure for any given value of the parameters. The empirical likelihood is multiplied by some relatively diffuse priors to obtain the posterior distribution of the parameters, and then this can be mapped using a Metropolis-Hastings algorithm. The BETEL approach can be used more generally than for quantile regressions. The moment conditions are derived from the condition that (for two variables $y_{i}$ and $x_{i}$ )

$$
\operatorname{Pr} y_{i}<\alpha \tau+\beta \tau x_{i} \mid x_{i}=\tau \text {. }
$$

The parameters $\alpha \quad \tau$ and $\beta$ l $\quad$ represent the intercept and slopes for the $\tau^{\text {th }}$ quantile. Like the nonparametric regressions, quantile regressions are run separately for each time period.

\section{Empirical Results}

Discussion of the results proceeds sequentially examining the nonparametric results first, followed by the panel regression results, and then the quantile results (focus is on the elasticity estimates with the full set of parameter estimates in the appendix). As stated, the nonparametric regressions were run separately over the two periods (1990-1992 and 20032005). Only the latter period is presented, since the nonparametric plots are almost the same between the two periods. First, figure 1 examines the raw nutrient shares modelled as a function of the raw per capita variable. The middle line is the fitted (mean) nonparametric relationship, with the two outside lines containing the $95 \%$ confidence intervals for the mean. As seen from the plots, the relationship between shares of nutrients and per capita income appears to be non-linear, with poorer countries having relatively high levels of carbohydrates as a proportion of their diet (top left hand corner of figure 1). As incomes increase, however, the shares of carbohydrates decrease with a small rise in proteins but a much larger rise in 
fats. In the poorest countries, about $80 \%$ to $85 \%$ of the diet is in the form of carbohydrates and only around $10 \%$ in fats. As incomes increase though, there is a rapid switch to fats, levelling off at around a 50\% share in carbohydrates and a $38 \%$ share in fats, with the remainder being proteins. Warnings from Drewnowski and Popkin (1997) on the possibility of a diet containing close to $30 \%$ of energy from fat has in fact become the norm.

The second set of nonparametric plots in figure 2 are for the logged calorie and nutrient consumptions regressed against logged per capita income (the relationships between the raw data were also examined, and these were highly nonlinear and are not presented). What is more interesting about the fitted curves using the logged data is that for each of the variable pairs, the nonparametric curves are quite linear. In other words, the data are consistent with being linear in logs, and therefore have constant elasticities. There is some evidence of a slightly lower slope at very low levels of per capital income for total calories, fats, and proteins. Surprisingly, however, the increase in consumption of these quantities towards the upper end of the income range does not appear to level off. This implies that as per capita incomes rise, a percentage increase in per capita incomes continues to give the same percentage increase in calories, along with increases in fats, proteins, and carbohydrates. Also evident is that the carbohydrate line is much flatter, meaning that increases in incomes are not leading to the same increases in carbohydrates as for fats and proteins. This is consistent with the nonparametric results using nutrient shares.

In view of the nonparametric results, the linear in log specifications represent plausible empirical characterizations of the relationships between calories/nutrients and per capita income. This hypothesis is explored further using parametric methods. As outlined in the methods section, a set of panel regressions are specified, where the variables have been logged prior to estimation. Before presenting parameter estimates, alternative specifications including only a quadratic term and excluding a cubic or quadratic term are investigated first. 
No other restrictions are imposed at this stage, with further restrictions investigated subsequently. The DIC for each of the models is computed, with the preferred model being the one with the lowest DIC. The results are presented in table 2. The models with the lowest DIC are highlighted in bold, and the linear (in variables) specification is preferred for total calories, protein, and fats. However, the quadratic model is preferred for carbohydrates. Results conclude that the panel results are broadly in concordance with the nonparametric results and suggest that calories, protein, and fats have approximately constant elasticities over per capita incomes. This is not the case, however, for carbohydrates. The restrictions on the parameters across the time periods are investigated in table 3 in order to test whether the relationships differ across the two periods (1990-2 and 2003-5). For these comparisons the linear models are used, even for carbohydrates. As can be seen from the results in table 3, while there is evidence that the constants in the models can be restricted across the two periods none of the models support constant elasticities across the two periods, suggesting that there have been changes in consumption patterns other than those driven by incomes.

Table 4 presents the elasticities from the panel approach. The linear model results are given in table 4 as well as results from a first-difference model. As mentioned above, the quadratic model is preferred for carbohydrates, therefore carbohydrates are discussed further below. Results in table 4 reveal that while the DIC does not support constant elasticities over the two periods, the differences in elasticities across the periods is very small. The calorie elasticity is about 0.09 for both periods and both have $95 \%$ elasticity confidence intervals contained within the interval $(0.072,0.104)$. Both protein and fat elasticities are significantly larger than the calorie elasticities (at about $0.14-0.15$ and $0.23-0.24$, respectively), whereas the carbohydrate elasticity is much smaller (at around 0.02-0.025). This is consistent with the previous results regarding nutrient shares. Overall, results suggest that a $10 \%$ increase in per capita incomes will lead to around a $1 \%$ rise in calorie consumption, but with the larger 
components being an increase in fat consumption, followed by protein consumption, with a very small increase in carbohydrate consumption. As already noted, however, the carbohydrate elasticity does not appear to be constant. To further investigate carbohydrate consumption the income elasticity is estimated at each level of income. These are plotted in figure 3 for the two time periods, which again are very similar. The basic picture that emerges is that the carbohydrate elasticity is around 0.10 for very low levels of income, decreasing at a decreasing rate from there on, but remaining positive until around \$US7500 per year. Beyond this point carbohydrate consumption has a negative elasticity.

The results for the quantile regressions are presented in table 5. Again, these are linear in $\log$ specifications for each of the variables. Table 5 reports the upper $75 \%$, the median, and the lower $25 \%$ percentile elasticity estimates. In all cases, for all quantiles, the results are very similar to the estimated elasticities from the panel results. Of central interest is whether there seems to be a divergence between the different percentile values. As can be seen by table 5, these are very small. A large divergence between the lower and the upper percentiles would mean that countries with a higher consumption (for a given level of per capita income) are responding differently to those with a lower consumption (for a given level of per capita income). For example, if for calories the $\beta 0.25$ was much smaller than $\beta 0.75$ then countries with lower consumption of calories or nutrients would be less responsive to income changes than those with relatively high consumption of calories. This, arguably would be the most worrying scenario, since increased incomes would be having the least effect on those with the lowest consumption, and increased incomes would be having the highest effect on those with the highest income. From table 5, however, the opposite tends to be true. For both periods, the majority of the variables have non-decreasing or increasing elasticities moving down the percentile groups. Therefore, those consuming relatively small amounts of calories 
or nutrients (for a given level of income) tend to be the most responsive to changes in the levels of income. As already noted though, the divergence between the quantiles is small.

\section{Discussion and Limitations}

There are two caveats associated with the results: the first involves limitations inherent in the data and the second involves a potential specification bias from omitted variables. First, the use of aggregate average per capita GDP as a measure of consumer income is not ideal. The nutrient consumption of different individuals or households may be affected in different ways by changes in GDP, which also may arise for different reasons. For example, sanctions and draughts may have similar effects to lower per capita GDP, however, the effect on food consumption from these two occurrences may be quite different. Thus, distributional questions such as how a given change in per capita GDP affects different food consumers or how such distributional consequences vary according to the cause of the change in GDP, are beyond the scope of this paper. Limitations with the FAO data have also received attention in the literature (Gabbert and Weikard 2001; Nube 2001; Smith 1998; Svedberg 1999, 2002). Measurement error may be present, specifically in regards to the margin of errors present in agricultural production statistics from developing countries. Obtaining reliable and consistent data on food production can be problematic, especially from countries in Sub-Saharan Africa and South Asia. Not only are food production systems complex in these countries but there is also a heavy reliance on subsistence agriculture, the output of which is often under-measured (if measured at all). In these cases, the per capita availability of nutrients in the FAO data may be underestimated (which can potentially result in over-estimated parameters and income elasticities).

The second caveat regarding potential specification bias involves omission of other variables in the models that may be correlated with per capita income, thereby biasing the income elasticity estimate. Maternal education and employment, which micro-level evidence 
has shown to be important in controlling for income, are examples (Behrman and Wolfe 1984; Sahn 1994; Glewwe 1999). Within the aggregate macroeconomic framework, data availability preclude their inclusion. Despite these limitations, the approach in this paper fits within a body of literature that examines the nutrient-income relationship at the aggregate level, and complements similar studies undertaken at a more disaggregate level.

To summarize, calories, fats, and proteins have positive significant income elasticities. The data on these variables are also consistent with having constant elasticities across the income range. Carbohydrate consumption is found to have high positive elasticities only at low income levels, becoming negative at high incomes. A quantile regression yields similar elasticity estimates to the nonparametric and panel approaches at both the upper and lower quantiles, but there is some evidence to suggest that higher consuming countries (for both calories and nutrient components) had slightly lower elasticities than for those in the lower quantiles. In line with the majority of previous studies, the small but positive income elasticities suggest that income growth will increase calorie consumption and increase all nutrient consumption for low income countries (below US\$7500). However, the elasticity estimates fall below the majority of existing estimates.

In terms of overall calorie consumption, a $10 \%$ rise in incomes is required for $1 \%$ rise in calorie consumption. Thus, rather large increases in income are needed for an improvement in the nutrition status of people in poorer countries. The implications for higher income countries are perhaps no less important. Findings suggest that this overall rise in calorie consumption as incomes rise holds also for rich countries. Thus, for countries that are already consuming well beyond the recommended calorie levels, further increases in income will lead to even larger consumption of calories. Moreover, the consumption of fat has the largest elasticity at around 2.5 that of overall calorie consumption, meaning that the larger component of increased calorie consumption will be in terms of fats. While these elasticities 
may seem small, in the absence of any other change in behavior, extrapolating current income growth predicts significant cumulative increase in calorie consumption that would exacerbate existing problems associated with obesity. Such has been the case in parts of Asia, like China, where economic growth paralleled marked increases in obesity rates (Popkin and $\mathrm{Ng} 2007$ ).

Comparing the elasticity estimates to the existing literature, the income elasticity of calories is on the smaller side, though closest in magnitude to estimates obtained in similar cross-country studies (Reutlinger and Selowsky 1976; Dawson 1997) and a few micro-level studies based on food intake diaries (Wolfe and Behrman 1983; Strauss and Thomas 1989; Bhargava 1991; Skoufias et al. 2009). Most studies that use individual or household level data typically find the income-calorie elasticity to be around 0.30 (Duncan and Strauss 1995). Making comparisons with regard to the income- macronutrients elasticities is more difficult since fewer results exist. Behrman and Doelalikar (1987) obtain an income-protein elasticity of about 0.20 , which is close to their income-calorie elasticity of 0.19 (they did not estimate elasticities for carbohydrates or fats). Fousekis and Lazaridies (2005) obtain a mean income elasticities of 0.39 for protein, 0.30 for carbohydrates, and 0.61 for fats and oils.

Overall, the results obtained in this paper have two important implications. First, the impact of economic growth on calorie and macronutrient intake is likely to be small and as substantial as some studies have concluded (Subramanian and Deaton 1996; Meng, Gong, and Wang 2009).In fact, some studies suggest that good nutrition is a driver of economic growth and therefore development policies should be geared specifically towards reducing chronic malnutrition in order to spur economic growth rather than focusing on economic growth to spur good nutrition (Correa and Cummins 1970; Strauss 1986; Strauss and Thomas 1998; Fogel 2004). Second, economic growth may also change the structure of diets and the composition of nutrient intakes. In particular, results here suggest that as countries become richer not only are calorie intakes on an increasing trajectory, but that diets become 
increasingly composed of fats rather than proteins or carbohydrates. These results are in accord with the nutrition transition hypothesis of Popkin (2004). Economic growth, while contributing to the alleviation of malnutrition, also results in diets that become composed more of fats, worsening rates of obesity and obesity-related diseases.

\section{Conclusion}

This paper examined the relationship between calorie/nutrient consumption and per capita incomes using a two-period panel of 171 countries and extends the literature in two important ways. First, the relationship between income and average calorie intake is disaggregated into important nutrient components: carbohydrates, proteins, and fats. The disaggregation of calorie intake permits the relationship with income to differ between each nutrient. Most of the literature on nutrition and income, especially in the development literature, focuses entirely on total energy (calorie) intake. While the income elasticity of calories infers how the total level of energy is affected by income, it reveals nothing about how income affects diet composition. The few studies that do estimate nutrient-income elasticities (Pitt and Rosenzweig 1985; Behrman and Deolalikar 1987; Behrman and Wolfe 1987; Skoufias et al. 2009) confine their analysis to a single country.

Second, this study employs three different estimators (nonparametric, parametric, and quantile) for a robust interpretation of the income-nutrient relationship. A nonparametric estimator allows the relationship between income and calorie or nutrient consumption to be non-linear and non-monotonic. The parametric panel estimator permits estimation of both 'within-country' and 'between-time' effects and allows for testing of changes in the relationship over time. The nonparametric estimator allows the relationship between income and nutrient consumption to differ along the income distribution. In other words, rich countries and poor countries are allowed to respond differently to increases in income. The quantile estimator lets the marginal effect of income on calorie/nutrient intake to be different 
over the entire intake distribution. In this case, the impact of income may be different between rich and poor countries, which consume calories at different levels, so improvements in income may not impart equal benefits. While some studies use both parametric and nonparametric estimators, few studies utilize quantile regression.

Results suggest that development strategies aimed at improving economic growth may be insufficient at improving nutrient intake and may at worst exacerbate problems of poor diet and obesity in both developing and developed countries. Even in the absence of targeted policies, the global economic crisis will likely worsen the quality of diets internationally. In response to falling incomes, households will turn to fatty and calorie-dense, but nutrient poor, inexpensive processed foods. As the composition of diets change towards more fatty foods, countries across the globe will experience deteriorating nutritional status and health. Global efforts to improve diets require the coordinated design and implementation of policies that can address the dual public health problems of nutrient excess and deficiency.

While this paper focused on macronutrients, micronutrient deficiency (primarily iron, vitamin A, iodine, and zinc) is also a problem, and it often goes in hand with obesity. According to the WHO (2010): "Global increases in overweight and obesity are attributable to a number of factors including a global shift in diet towards increased intake of energydense foods that are high in fat and sugars but low in vitamins, minerals and other micronutrients." Micronutrient deficiency can cause or exacerbate a number of health and economic problems including blindness, early mortality, stunted mental development, and reduced labor productivity (UNICEF 2004). The empirical relationship between income and micronutrient consumption remains a viable area for future research. 


\section{REFERENCES}

Abdulai, A., and D. Aubert. 2004. Nonparametric and parametric analysis of calorie consumption in Tanzania. Food Policy 29(2): 113-129.

Aromolaran, A.B. 2004. Household income, women's income share and food calorie intake in South Western Nigeria. Food Policy 29(5): 507-530.

Babatunde, R.O., A.O. Adejobi, and S.B. Fakayode. 2010. Income and calorie intake among farming households in rural Nigeria: results of parametric and nonparametric analysis. Journal of Agricultural Science 2(2): 135-146.

Behrman, J.R., and A.B. Deolalikar. 1987. Will developing country nutrition improve with income? Journal of Political Economy 95(3): 492-507.

Behrman, J.R., and A.B. Deolalikar. 1989. Is variety the spice of life? Implications for calorie intake. Review of Economics and Statistics 71(4): 666-672.

Behrman, J.R., A.B. Deolalikar, and B.L. Wolfe. 1988. Nutrients: impacts and determinants. World Bank Economic Review 2(3): 299-320.

Behrman, J.R., and B.L. Wolfe. 1984. More evidence on nutrition demand: income seems overrated and women's schooling underemphasized. Journal of Development Economics 14(1): 105-128.

Behrman, J.R.., and B.L. Wolfe. 1987. How does mother's schooling affect family health, nutrition, medical care usage, and household sanitation? Journal of Econometrics 36(12): $185-204$.

Bhargava, A. 1991. Estimating short and long run income elasticities of foods and nutrients for rural South India. Journal of the Royal Statistical Society (Series A) 154(1): 157174. 
Bouis, H.E. 1994. The effect of income on demand for food in poor countries: are our food consumption databases giving us reliable estimates? Journal of Development Economics 44(1): 199-226.

Bouis, H.E., and L.J. Haddad. 1992. Are estimates of calorie-income elasticities too high? A recalibration of the plausible range. Journal of Development Economics 39(2): 333364.

Caballero, B. 2005. A nutrition paradox -- underweight and obesity in developing countries. New England Journal of Medicine 352(15): 1514-1516.

Chibb, S. and E. Greenberg 1995. Hierarchical analysis of SUR models with extensions to correlated serial errors and time-varying parameter models. Journal of Econometrics 68(2): 339-360.

Correa, H., and G. Cummins. 1970. Contribution of nutrition to economic growth. American Journal of Clinical Nutrition 23(5): 560-565.

Dawson, P.J. 1997. The demand for calories in developing countries. Oxford Development Studies 25(3): 361-369.

Dawson, P.J. 2002. Nutrition in Pakistan: estimating the economic demand for calories. Pakistan Journal of Nutrition 1(1): 64-66.

Dawson, P.J., and R. Tiffin. 1998. Estimating the demand for calories in India. American Journal of Agricultural Economics 80(3): 474-481.

Doak, C.M., L.S. Adair, M. Bentley, C. Monteiro, and B.M. Popkin. 2005. The dual burden household and the nutrition transition paradox. International Journal of Obesity 29(1): 129-136.

Drewnowski, A. 2003. Fat and sugar: an economic analysis. Journal of Nutrition 133(3): 838S-840S. 
Drewnowski, A., and B.M. Popkin. 1997. The nutrition transition: new trends in the global diet. Nutrition Reviews 55(2): 31-43.

Food and Agriculture Organization. 2009. State of Food Insecurity in the World. Rome, Italy. Fogel, R.W. 2004. Health, nutrition, and economic growth. Economic Development and Cultural Change 52(3): 643-658.

Fousekis, P., and P. Lazaridis. 2005. The demand for selected nutrients by Greek households: an empirical analysis with quantile regressions. Agricultural Economics 32(3): 267279.

Gabbert, S., and H.-P. Wiekard. 2001. How widespread is undernourishment: A critique of measurement methods and new empirical results. Food Policy 26(3): 209-228.

Gibson, J., and S. Rozelle. 2002. How elastic is calorie demand? Parametric, Nonparametric and Semiparametric results for urban Papua New Guinea. Journal of Development Studies 38(6): 23-46.

Glewwe, P. 1999. Why does mother's schooling raise child health in developing countries? Evidence from Morocco. Journal of Human Resources 34(1): 124-159.

Grimard, F. 1996. Does the poor's consumption of calories respond to changes in income? Evidence from Pakistan. Pakistan Development Review 35(3): 257-283.

Hossain, P., B. Kawar, and M. El Nahas. 2007. Obesity and diabetes in the developing world: a growing challenge. New England Journal of Medicine 356(13): 213-215.

Koop G. 2003. Bayesian Econometrics. Sussex, England: Wiley.

Lancaster T. and Sung .J.J. 2010. Bayesian Quantile Regression Methods. Journal of Applied Econometrics 25(2): 287-307.

Meng, X., X. Gong, and Y. Wang. 2009. Impact of growth and economic reform on nutrition availability in urban China: 1986-2000. Economic Development and Cultural Change 57(2): 261-295. 
Nube, M. 2001. Confronting dietary energy supply with anthropometry in the assessment of undernutrition prevalence at the level of countries. World Development 29(7): 12751289.

Pinstrup-Andersen P. 2007. Agricultural research and policy for better health and nutrition in developing countries: a food systems approach. Agricultural Economics 37(S1):187198.

Pinstrup-Andersen, P., and E. Caicedo. 1978. The potential impact of changes in income distribution on food demand and human nutrition. American Journal of Agricultural Economics 60(3): 402-415.

Pitt, M.M. 1983. Food preferences and nutrition in rural Bangladesh. Review of Economics and Statistics 65(1): 105-114.

Pitt, M.M., and M.R. Rosenzweig. 1985. Health and nutrient consumption across and within households. Review of Economics and Statistics 67(2): 212-223.

Popkin, B.M. 1994. The nutrition transition in low-income countries: an emerging crisis. Nutrition Reviews 52(9): 285-298.

Popkin, B.M. 2004. The nutrition transition: worldwide obesity dynamics and their determinants. International Journal of Obesity 28: S2-S9.

Popkin, B.M., and S.W. Ng. 2007. The nutrition transition in high- and low-income countries: what are the policy lessons? Agricultural Economics 37(S1): 199-211.

Ravallion, M. 1990. Income effects on undernutrition. Economic Development and Cultural Change 38(3): 489-515.

Reutlinger, S. and M. Selowsky. 1976. Malnutrition and poverty: magnitude and policy options. World Bank staff occasional papers no. 23; Johns Hopkins University Press. Baltimore, USA. 
Roy, N. 2001. A semiparametric analysis of calorie response to income change across income groups and gender. Journal of International Trade and Economic Development 10(1): 93-109.

Sahn, D.E. 1988. The effect of price and income changes on food-energy intake in Sri Lanka. Economic Development and Cultural Change 36(2): 315-340.

Shankar, B. 2010. Socio-economic drivers of overnutrition in China. Journal of Human Nutrition and Dietetics 23(5): 471-479.

Skoufias, E. 2003. Is the calorie-income elasticity sensitive to price changes? Evidence from Indonesia. World Development 31(7): 1291-1307.

Skoufias, E., V. Di Maro, T. Gonzalez-Cossiom, and S. Rodriguez Ramirez. 2009. Nutrient consumption and household income in rural Mexico. Agricultural Economics 40(6): 657-675.

Smith, L. 1998. Can FAO's measure on chronic undernourishment be strengthened? Food Policy 23(5): 425-445.

Spiegelhalter D.J., N.G. Best, B.P. Carlin, and A. van der Linde. 2002. Bayesian Measures of Model Complexity and Fit. Journal of the Royal Statistical Society: Series B (Statistical Methodology) 64 (4): 583 - 639.

Strauss, J. 1986. Does better nutrition raise farm productivity? Journal of Political Economy 94(2): 297-320.

Strauss, J., and D. Thomas. 1998. Health, nutrition, and economic development. Journal of Economic Literature 36(2): 766-817.

Subramanian, S., and A. Deaton. 1996. The demand for food and calories. Journal of Political Economy 104(1): 133-162.

Svedberg, P. 1999. 841 million undernourished? World Development 27(12): 2081-2098. 
Svedberg, P. 2003. Undernutrition overestimated. Economic Development and Cultural Change 51(5): 5-36.

Tiffin, R. and P.J. Dawson. 2002. The demand for calories: some further estimates from Zimbabwe. Journal of Agricultural Economics 53(2): 221-232.

UNICEF. 2004. Vitamin and Mineral Deficiency, A Global Progress Report. NY: New York.

Ward, J.O., and J.H. Sanders. 1980. Nutritional determinants and migration in the Brazilian Northeast: a case study of rural and urban Ceará. Economic Development and Cultural Change 29(1): 141-163.

Wolfe, B.L. and J.R. Behrman. 1983. Is income overrated in determining adequate nutrition? Economic Development and Cultural Change 31(3): 525-549.

World Bank. 1980. World Development Report. Washington, DC: USA.

World Bank. 1981. World Development Report. Washington, DC: USA.

World Health Organization. 2004. Global Strategy on Diet, Physical Activity and Health. Geneva: Switzerland.

World Health Organization. 2006. Obesity and Overweight Factsheet. Geneva: Switzerland. 
Table 1. Summary of Recent Studies

\begin{tabular}{lllllll}
\hline Author & Year & Data Level & Model & Timeframe & Country & $\begin{array}{l}\text { Calorie } \\
\text { Elasticity }\end{array}$ \\
\hline Bhargava & 1991 & Individual & Panel & $1976-1977$ & India & 0.13 \\
Grimard & 1996 & Household & Cross-sectional & $1984-1985$ & Pakistan & $0.40-0.50$ \\
Subramanian and Deaton & 1996 & Household & Cross-sectional & 1983 & India & $0.40-0.55$ \\
Dawson & 1997 & Aggregate & Cross-sectional & 1992 & 41 DCs & 0.07 \\
Dawson and Tiffin & 1998 & Aggregate & Time-series & $1961-1992$ & India & 0.34 \\
Roy & 2001 & Individual & Panel & $1976-1978$ & India & $<0-0.15$ \\
Dawson & 2002 & Aggregate & Time-series & $1961-1998$ & Pakistan & 0.19 \\
Gibson and Rozelle & 2002 & Household & Cross-sectional & $1985-1987$ & Papua New Guinea & $0.18-0.59$ \\
Tiffin and Dawson & 2002 & Aggregate & Time-series & $1961-1992$ & Zimbabwe & 0.31 \\
Skoufias & 2003 & Household & Cross-sectional & 1996,1999 & Indonesia & $0.01-0.45$ \\
Abdulai and Aubert & 2004 & Household & Panel & $1998-1999$ & Tanzania & 0.49 \\
Aromolaran & 2004 & Household & Cross-sectional & $1999-2000$ & Nigeria & 0.19 \\
Skoufias et al. & 2009 & Household & Cross-sectional & $2003-2004$ & Mexico & $<0-0.07$ \\
Meng, Gong, and Wang & 2009 & Household & Panel & $1986-2000$ & China & $0.20-0.49$ \\
Babatunde et.al & 2010 & Household & Cross-sectional & 2006 & Nigeria & 0.18 \\
\hline
\end{tabular}


Table 2. DIC for Functional Forms

\begin{tabular}{lcccc}
\hline & Calories & Carbs & Protein & \multicolumn{1}{c}{ Fats } \\
\hline Cubic & -1180.25 & -1109.16 & -966.52 & -738.66 \\
Quadratic & -1178.46 & $\mathbf{- 1 1 0 9 . 5 6}$ & -967.91 & -738.32 \\
Linear & $\mathbf{- 1 1 8 0 . 9 3}$ & -1102.93 & $\mathbf{- 9 6 9 . 2 8}$ & $\mathbf{- 7 4 1 . 5 7}$ \\
\hline
\end{tabular}


Table 3. DIC for Restrictions Across Periods for Linear Models

\begin{tabular}{lcccc}
\hline & Calories & Carbs & Protein & Fats \\
\hline Unrestricted & -1180.93 & -1102.93 & -969.28 & $\mathbf{- 7 4 1 . 5 7}$ \\
Constant Elasticities & -1178.20 & -1103.60 & -969.27 & -733.40 \\
Constant Intercept & $\mathbf{- 1 1 8 2 . 6 0}$ & $\mathbf{- 1 1 0 4 . 8 3}$ & $\mathbf{- 9 7 1 . 2 7}$ & -739.89 \\
Constant All Parameters & -1151.22 & -1090.24 & -947.37 & -716.88 \\
\hline
\end{tabular}


Table 4. Elasticity Estimates from Linear Panel Regression

\begin{tabular}{lcccccccc}
\hline & \multicolumn{2}{c}{ Calories } & \multicolumn{2}{c}{ Carbohydrates } & \multicolumn{2}{c}{ Proteins } & \multicolumn{2}{c}{ Fats } \\
\hline & Mean & Stdv & Mean & Stdv & Mean & Stdv & Mean & Stdv \\
\hline $2003-2005$ & 0.086 & 0.006 & 0.020 & 0.007 & 0.140 & 0.009 & 0.230 & 0.014 \\
$1990-1992$ & 0.092 & 0.006 & 0.025 & 0.007 & 0.148 & 0.009 & 0.241 & 0.014 \\
First-Difference & 0.074 & 0.030 & 0.026 & 0.036 & 0.162 & 0.041 & 0.209 & 0.060 \\
\hline
\end{tabular}


Table 5. Quantile Elasticity Estimates

\begin{tabular}{rrrrrrrrrr}
\hline & \multicolumn{4}{c}{ Calories } & \multicolumn{2}{c}{ Carbohydrates } & \multicolumn{2}{c}{ Proteins } & \multicolumn{2}{c}{ Fats } \\
\hline $2003-05$ & beta & stdv & beta & stdv & beta & stdv & beta & stdv \\
\hline$\tau=0.75$ & 0.083 & 0.009 & 0.016 & 0.007 & 0.130 & 0.012 & 0.197 & 0.020 \\
$\tau=0.50$ & 0.088 & 0.007 & 0.020 & 0.009 & 0.140 & 0.007 & 0.229 & 0.016 \\
$\tau=0.25$ & 0.089 & 0.010 & 0.026 & 0.010 & 0.152 & 0.011 & 0.257 & 0.024 \\
\hline $1990-92$ & beta & stdv & beta & stdv & beta & stdv & beta & stdv \\
\hline$\tau=0.75$ & 0.093 & 0.008 & 0.019 & 0.007 & 0.137 & 0.012 & 0.217 & 0.018 \\
$\tau=0.50$ & 0.094 & 0.007 & 0.019 & 0.010 & 0.147 & 0.010 & 0.264 & 0.021 \\
$\tau=0.25$ & 0.094 & 0.008 & 0.028 & 0.007 & 0.156 & 0.014 & 0.274 & 0.027 \\
\hline
\end{tabular}



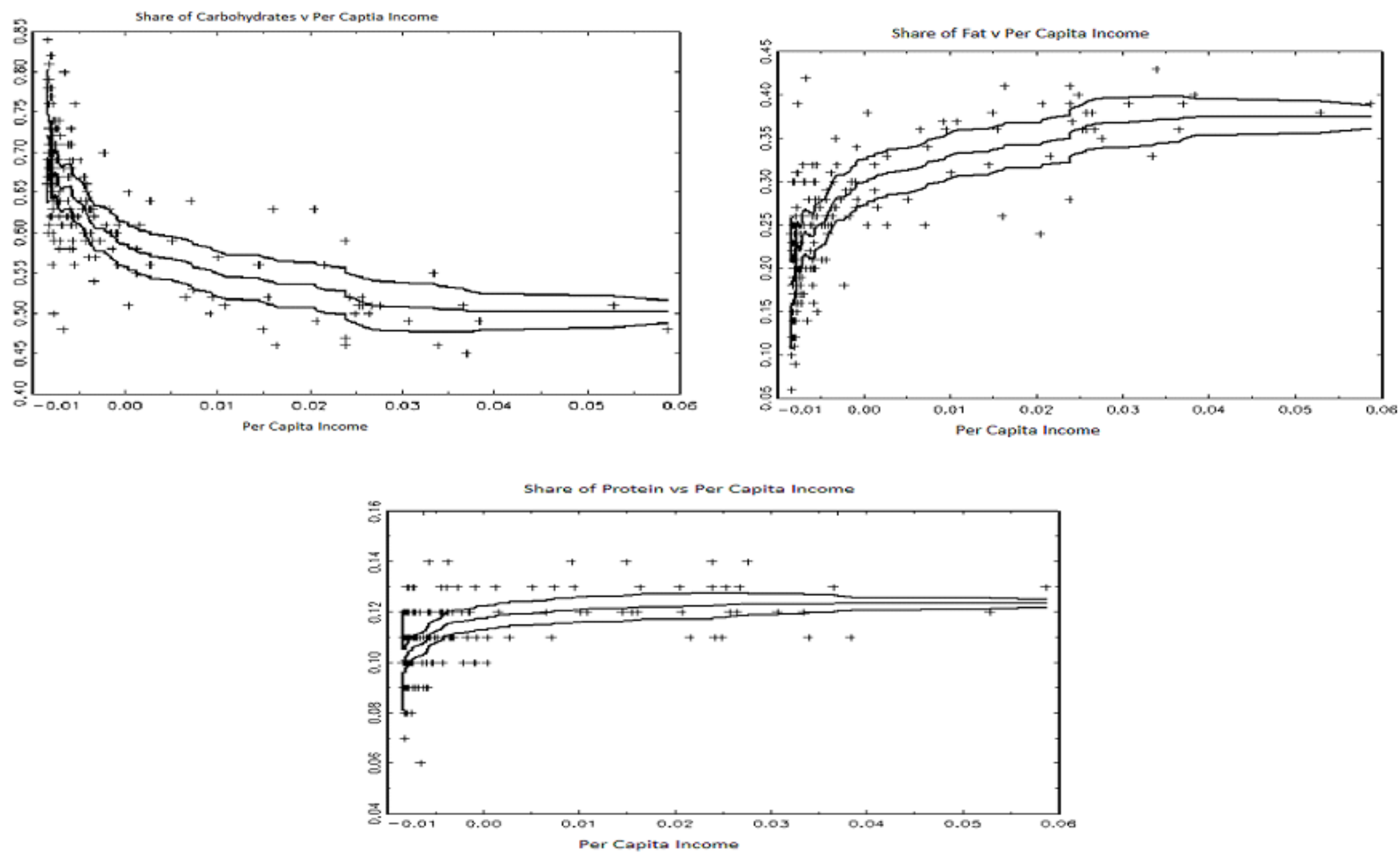

Figure 1. Nutrient shares versus per capita income 

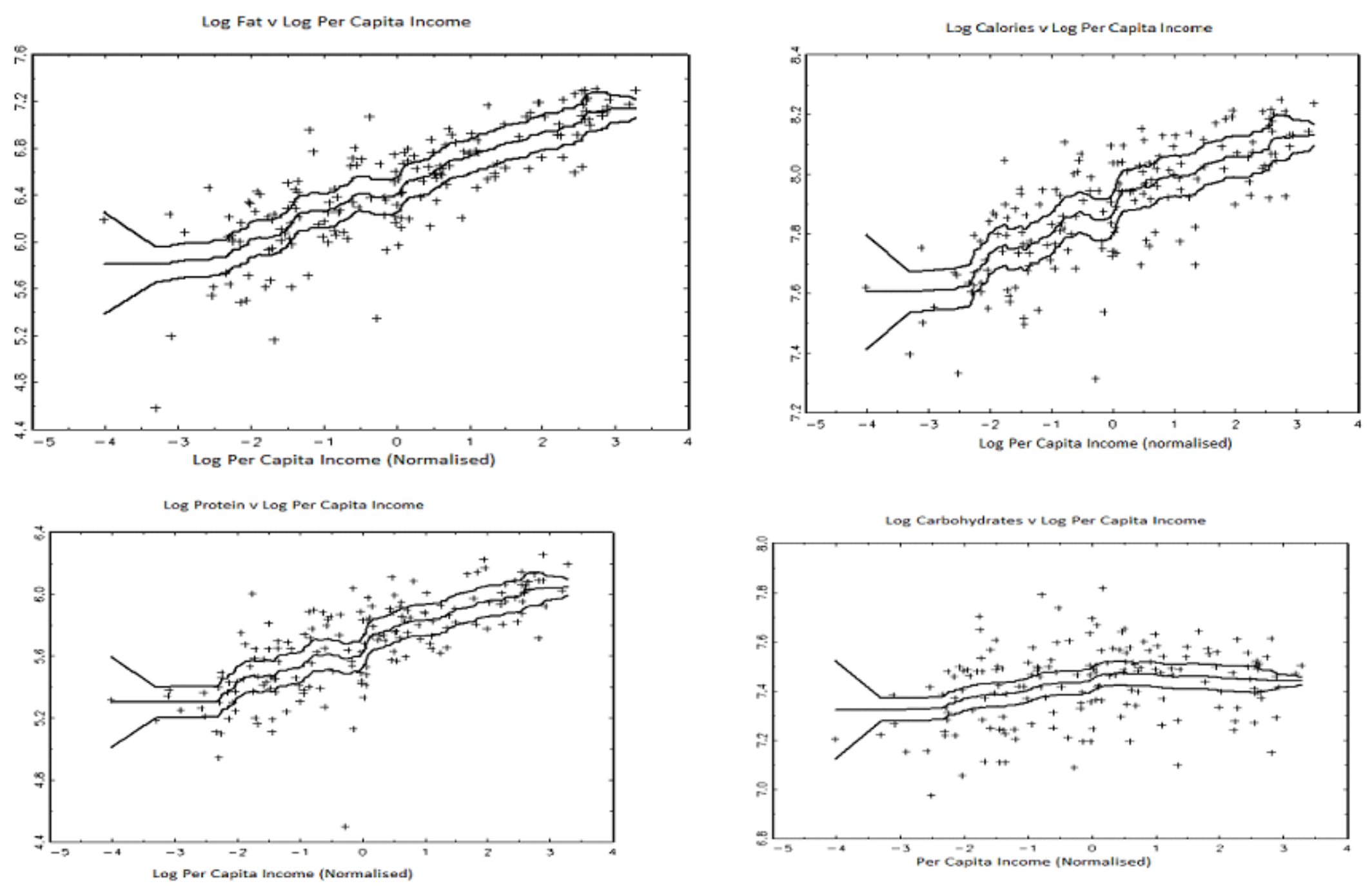

Figure 2. Log nutrient consumption versus per capita income 
Elasticity of Carbohydrates v Per Capita Income

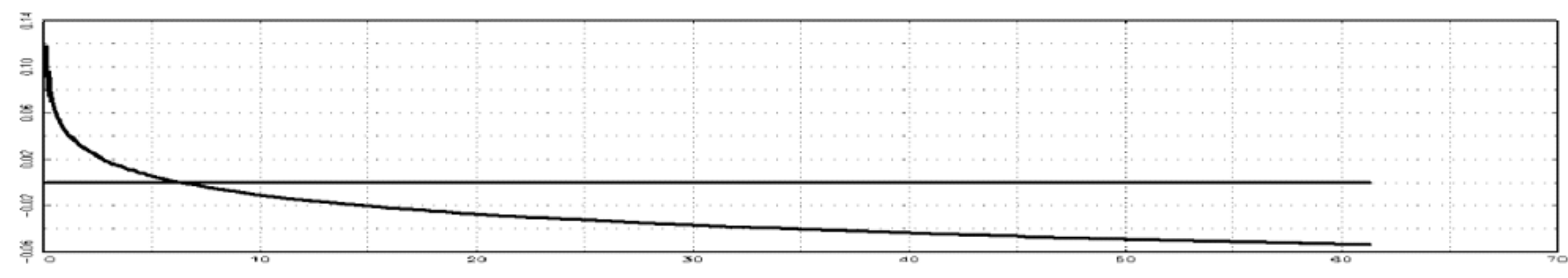

Per Capita Income (\$1000s) 2003-2005

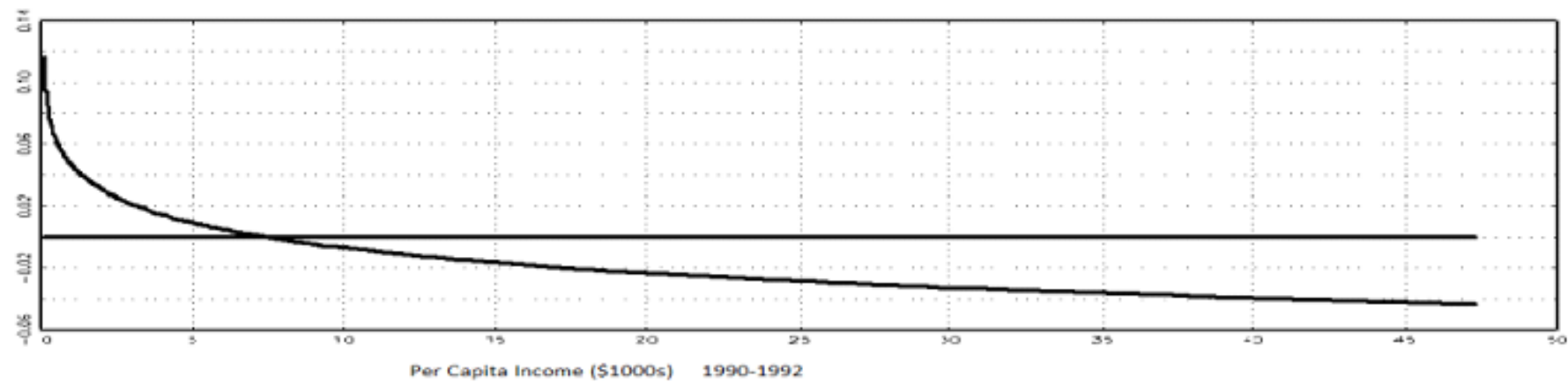

Figure 3. Carbohydrate income elasticity 